\title{
Diseño de comunicación municipal para la ciudad de Santa Fe Procesos de hibridación cultural*
}

Lic. Estefanía Fantini, fadu/unL

«...Ubicar al diseño como sinónimo de comunicación sin pensar críticamente en lo que implica la "sociedad de la comunicación" es, en la mayoría de los casos, una actitud ingenua que, por lo menos, quita profundidad al pensamiento, convirtiéndose en obstáculo para dar el salto entre un técnico en diseño gráfico y un operador cultural...» (Ledesma, 2003:35. La negrita me pertenece)

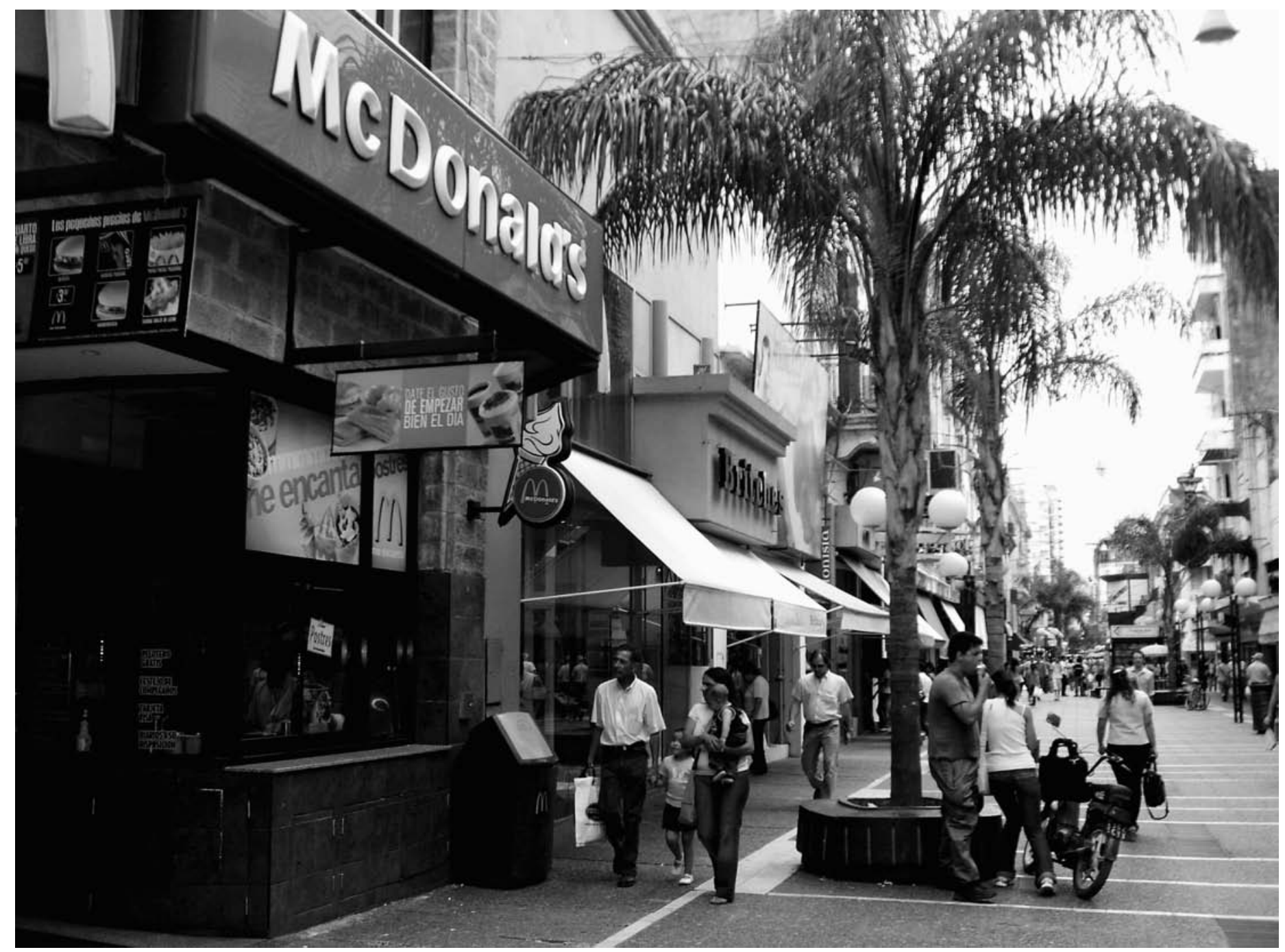

Peatonal San Martín. El trasplante de costumbres propias de otras formas culturales que comienzan a vivirse como propias, es uno de los referentes principales de un ciclo de hibridación. 
El tema de nuestra tesina fue el diseño de comunicación municipal en relación con los procesos de hibridación cultural (Canclini) detectados en la ciudad de Santa Fe. Desde esta perspectiva, el desafío de la investigación consistió en hallar axiologías comunes para que los públicos, caracterizados por su diversidad, se viesen representados y se sintieran partícipes de sus instituciones de gobierno.

Con este propósito se partió de un reconocimiento del contexto situacional y de acción (Ledesma, 2003:100) a fin de identificar las vacancias existentes respecto de la comunicación municipal específicamente.

Tomar la propuesta de Canclini como eje de trabajo, su- puso en primer lugar, poner en crisis los abordajes teórico-metodológicos para la producción de discursos identitarios para instituciones gubernamentales, debido a su carácter típicamente homogeneizante y en segundo lugar, generar un marco teórico para nuestra tesina referenciado en la vertiente de los estudios culturales.

Se seleccionaron para su construcción las categorías de cultura, hibridación, identidad, imaginario, contexto y comunicación municipal, constituyendo una red conceptual que contempló también una serie de conceptos anexos que sirvieron a un abordaje más profundo del problema objeto de estudio.

Nos interesa detenernos aquí en la propuesta de García

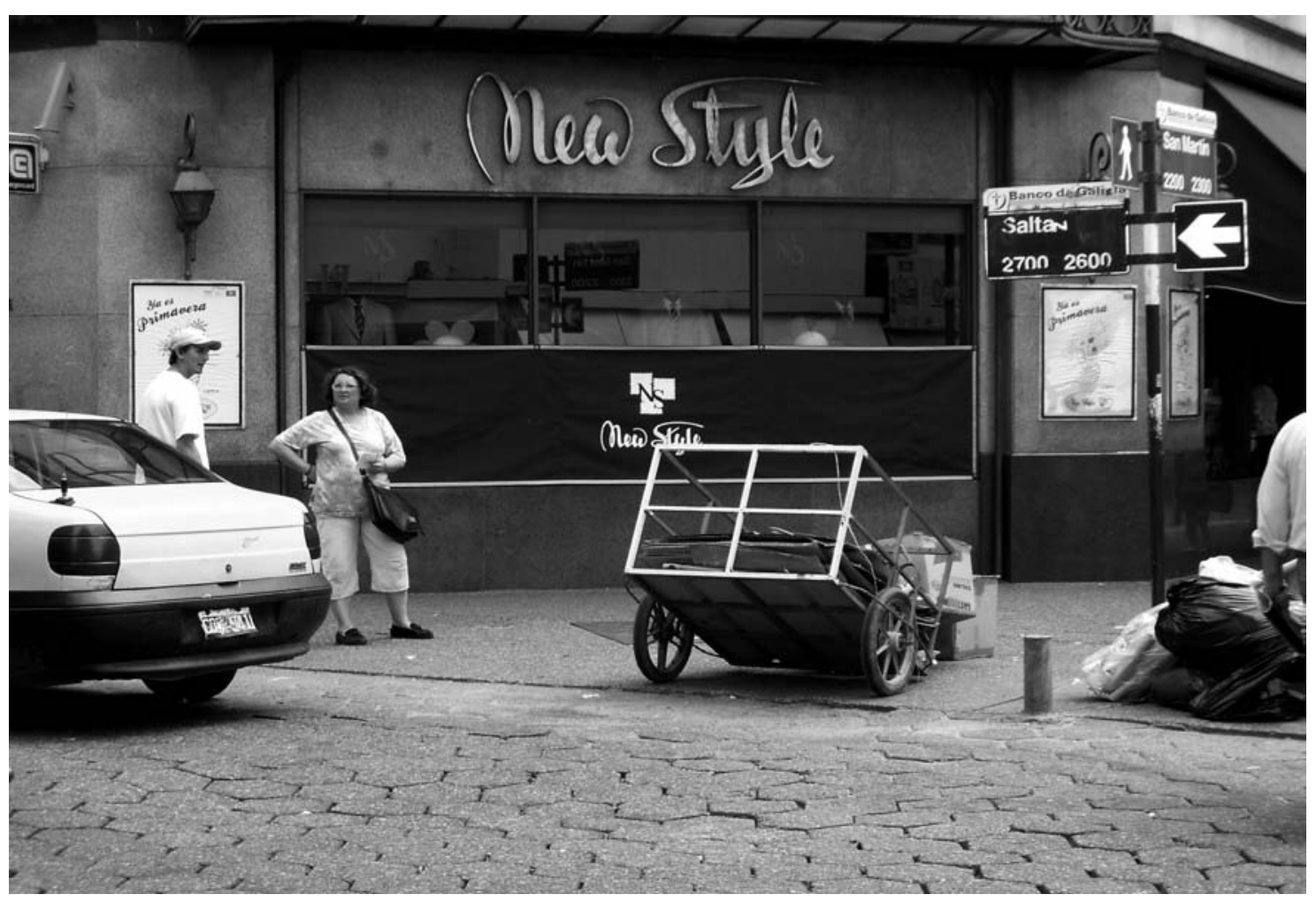

Calle Salta y San Martín. La convivencia de múltiples sectores sociales en la ciudad, generan muchas veces situaciones de tensión, debido a la restricción de los procesos de hibridación. 
Lo territorial, identidad que se define por la diferencia con el otro cultura haciéndose como costura (Salaber, 1988:10. En: Silva, 1997:62). Créditos de la imagen: http://www.flickr.com

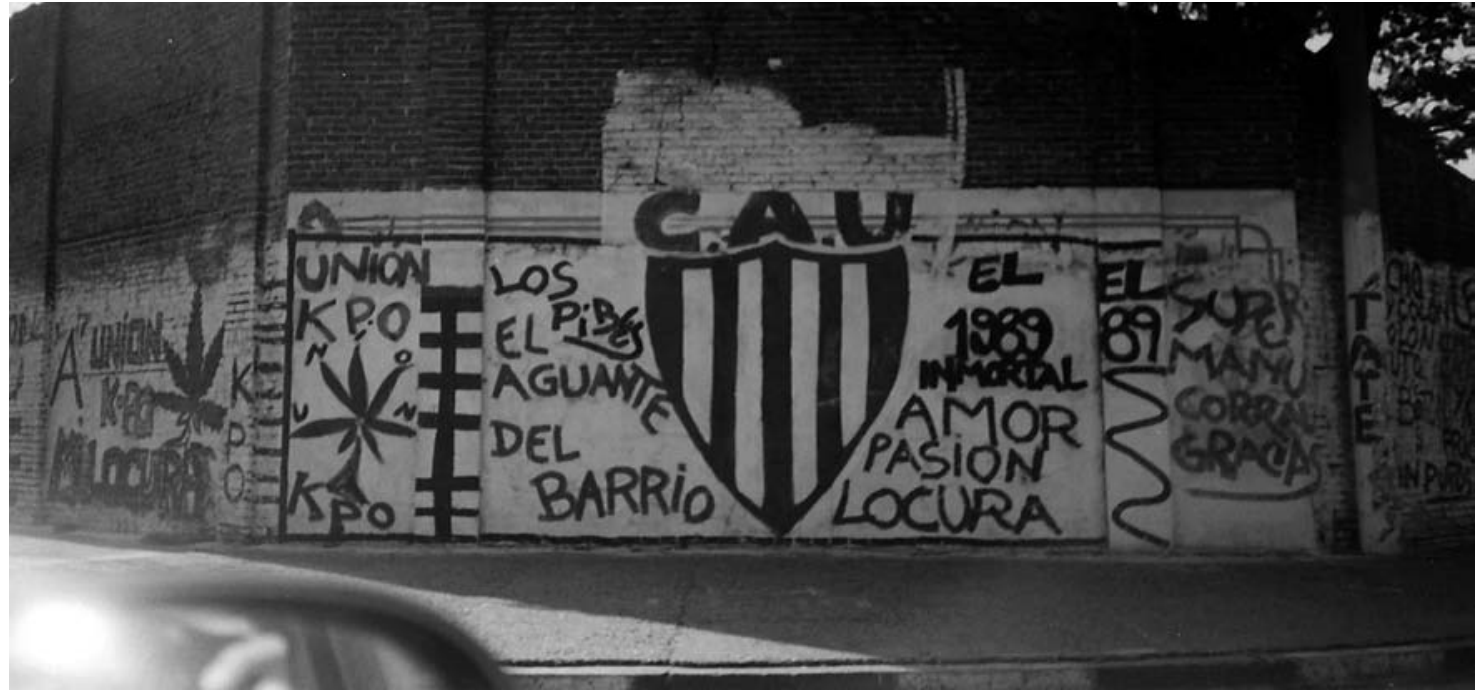

Canclini que define al citado concepto de la siguiente manera: «entiendo por hibridación procesos socioculturales en los que estructuras prácticas o discretas, que existían en forma separada, se combinan para generar nuevas estructuras, objetos y prácticas. A su vez, cabe aclarar que las estructuras Ilamadas discretas fueron resultado de hibridaciones, por lo cual no pueden ser consideradas fuentes puras». (García Canclini, 2001:14) Teniendo en cuenta que nuestro estudio indaga en la importancia de un discurso identitario de carácter visual coherente para la ciudad (y por ello contempla una emisión y una recepción particularizada), debimos subrayar la existencia de situaciones tensionantes que Canclini ha llamado ciclos de hibridación (García Canclini, 2001:15), y actualmente constituyen una forma atinada de pensar las identidades modernas, que entran en períodos más 0 menos críticos, debido a restricciones o consecuciones en los procesos hibridantes: «¿cómo designar las fusiones entre culturas barriales y mediáticas, entre estilos de consumo de generaciones diferentes, entre músicas locales y transnacionales, que ocurren en las fronteras y en las grandes ciudades?» (García Canclini, 2001: 22). En la etapa de desarrollo de la investigación, se articularon los planteos que desde el campo disciplinar del Diseño enuncian distintos lineamientos para generar intervenciones de identidad, que en una relectura modificada por las conceptualizaciones presentes en el marco teórico, propiciaron el cruce de teorías necesario para elaborar la propuesta final en la tesina.

La misma, consistió en un modelo alternativo apto para aunar los siguientes bloques: la perspectiva sociológica, aporte fundamental para estudiar a los públicos ciudadanos; una perspectiva comunicativa capaz de concebir al público como entidad activa teniendo en cuenta la importancia del código ${ }^{1}$; la perspectiva de las teorías del diseño respecto de la imagen corporativa, en aquellos aspectos beneficiosos para la especificidad de la comunicación municipal.

Además, la propuesta modélica, se estructuró según las dos grandes etapas que Chaves postula para la proyectación de imagen corporativa: la analítica y la normativa, renombrada como proyectiva, ya que contempla la construcción de un identificador visual a nivel ciudad (Fernández, 2001), resolviendo un esquema de trabajo de la siguiente manera (ver esquema).

En este trabajo, se propuso (tal como lo hace Puig) a la esfera del público dentro del primer momento de trabajo analítico, desde donde decantaron los conceptos y atributos necesarios para establecer una estrategia de comunicación pertinente.

Luego, se insertó la primera fase de la etapa normativa propuesta por Chaves, que refiere a la formulación de la estrategia general de la intervención, (Chaves, 1994:112), según la cual, esos conceptos y atributos sondeados irán a definir la calidad que la intervención de diseño pueda tener, continuando con las instancias propuestas por Puig hasta llegar a la implementación.

El capítulo final de la tesina, muestra la aplicación del modelo descripto para generar comunicación municipal en la ciudad de Santa Fe. Proyectualmente este trabajo se reflejó en la producción de un sello de ciudad (Puig) y un símbolo de actualidad para el municipio.

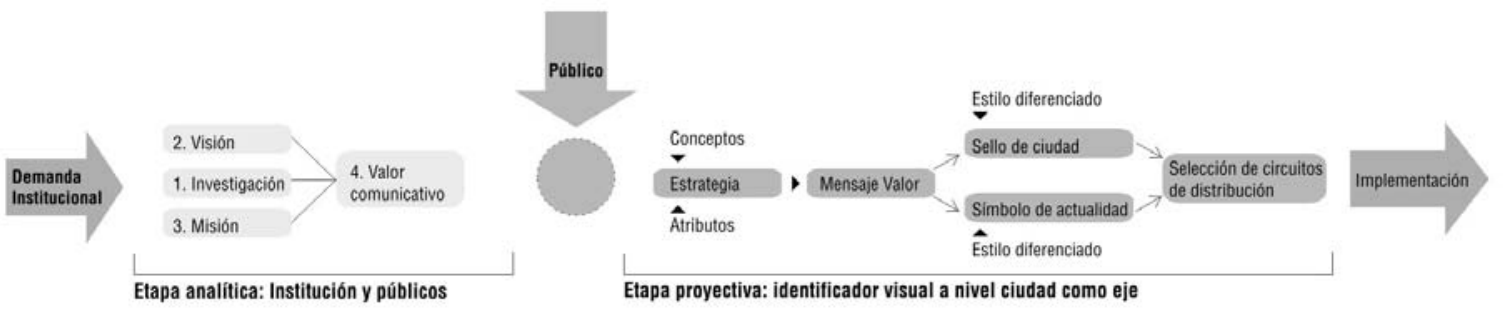




\section{Bibliografía}

Altamirano, C. (2002): Términos críticos de Sociología de la Cultura. Paidós, Buenos Aires.

Althusser, L. (1984): Ideología y aparatos ideológicos de Estado. Nueva visión, Buenos Aires.

Baczko, B. (1999): Los imaginarios sociales. Memorias y esperanzas colectivas. Nueva Visión, Bs. As.

Castells, M. (2004): La era de la información. Vol. 2: El poder de la identidad. Siglo xxi Editores, México.

Costa, J. (2003): Imagen corporativa en el siglo XXI. La Crujía, Buenos Aires.

Costa J. (2004): La imagen de marca. Un fenómeno social. Paidós, Barcelona.

Cháves, N. y Belluccia, R. (2006): La marca corporativa. Gestión y diseño de símbolos y logotipos. Paidós, Buenos Aires.

Cháves, N. (1988): La imagen corporativa. Teoría y metodología de la identificación institucional. Gustavo Gilli, Barcelona.

Fernández, S. (2004): «No marca país». Tipográfica, Nº 63 . Buenos Aires.

García Canclini, N. (1995): Consumidores y ciudadanos. Conflictos multiculturales de la globalización. Grijalbo, México.

García Canclini, N. (2001): Culturas híbridas. Estrategias para entrar y salir de la modernidad. Paidós (Estado y sociedad), Argentina.

García Canclini, N. (1997): «El malestar en los estudios culturales». Revista Fractal, N $^{\circ}$ 6, vol. 2.

García Canclini, N. (1997): Imaginarios urbanos. EUDEBA, Buenos Aires.

García Canclini, N. (2002): Latinoamericanos buscando lugar en este siglo. Paidós, Buenos Aires.

Greimás, A. y Courtés, J. (1990): Diccionario razonado de la teoría del lenguaje. Gredos, Madrid.
Grimson, A. (2000): Interculturalidad y comunicación. Grupo Editorial Norma, Buenos Aires.

Guerri, C. (2003): El nonágono semiótico: un ícono diagramático y tres niveles de iconicidad.

En: De Signis, no ${ }^{\circ}$. Iconismo. El sentido de las imágenes.

Capítulo 1, apartado 4. Editorial Gedisa, Barcelona.

Guerri, C. (2004): «El nonágono semiótico».

Revista Polis, Edición especial de Diseño.

Ediciones unl. Santa Fe, Argentina.

Ledesma, M. (2003): El diseño gráfico, una voz pública. Argonauta, Buenos Aires.

Ledesma, M; Arfuch, L; Chaves, N. (1997): Diseño y comunicación (teorías y enfoques críticos). Editorial Paidós, Buenos Aires.

Magariños de Morentín, J. (1983): El signo. Las fuentes teóricas de la semiología: Saussure, Pierce, Morris. Edicial, Buenos Aires.

Morace, F. (1993): Contratendencias. Una nueva cultura del consumo. Experimenta Ediciones de Diseño, Madrid.

Ortiz, R. (2002): Globalización/mundialización. En: Altamirano, C. (comp): Términos críticos de sociología de la cultura. Paidós, Buenos Aires.

Puig, T. (2003): La comunicación municipal, cómplice con los ciudadanos. Paidós, Buenos Aires.

Silva, A. (1998): Imaginarios urbanos. Cultura y comunicación urbana. Tercer Mundo Editores. Santafé de Bogotá, Colombia.

Williams, R. (1981): Cultura. Sociología de la comunicación $y$ del arte. Paidós Comunicación, Barcelona.

Williams, R. (1997): Marxismo y literatura. Península, Barcelona.

Williams, R. (200o): Palabras clave. Un vocabulario de la cultura y la sociedad. Nueva Visión, Buenos Aires.

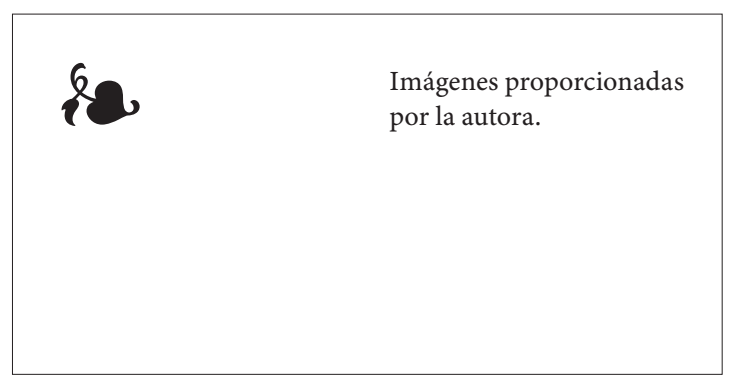

